\title{
Photocatalytic Degradation of Thiram (Fungicides) under Visible Light Irradiation
}

\author{
SANJAY R.THAKARE* and N.S.BHAVE \\ *Department of Chemistry, \\ Science College, Congress Nagar. Nagpur (India) 400012 \\ Department of Chemistry, \\ Nagpur University Campus, Nagpur (India) 440009
}

Received 14 October 2004; Accepted 14 December 2004

\begin{abstract}
Pesticides in the different form are toxic to the environment and removal of its form the various sources is a difficult task. The thiram undergoes photocatalytic degradation under visible light when prepared $\mathrm{TiO}_{2} \sim \mathrm{PVA}$ polymer composite was used as a photocatalyst. The data represent that prepared $\mathrm{TiO}_{2} \sim \mathrm{PVA}$ polymer composite is a more efficient photocatalyst than the neat $\mathrm{TiO}_{2}$. Photocatalytic efficiency of prepared $\mathrm{TiO}_{2} \sim \mathrm{PVA}$ polymer composite was measured in term of no adsorption of pollutant, higher degradation rate and act as a photocatalyst under visible light irradiation. 150 minutes are required for the complete degradation of the thiram. The end products of photocatalytic degradation of thiram are $\mathrm{CO}_{2}$, nitrate and sulphate.
\end{abstract}

Key words: Photocatalysis, Pesticides, thiram, visible light, mineralisation.

\section{Introduction}

Cultivation of plants for economical purposes requires a constant struggle against losses from pests promoted by weeds, insects, diseases, etc. The most frequents agents used for this objectives are pesticides in their different forms such as insecticides, herbicides, fungicides etc. All of them have contributed in a great extent to agricultural productivity. However pesticides pollution of surface waters and wastewaters has increased sharply and presently it constitutes a major pollutants problem due to an extensive use of these substances. Water pollution caused by hazardous materials is becoming a serious problem globally. The contaminants of numerous chemicals from industry, agriculture and domestic use must be eliminated. Since such chemicals as fungicides, herbicides, insecticides, disinfectants, antimicrobials and nematicides are difficult to decompose by biodegradation through biological agents such as bacteria, they accumulates in nature and persist for the long time. When irradiated by UV light, the heterogeneous $\mathrm{TiO}_{2}$ catalyst exhibit very strong oxidizing and reducing properties in presence of oxygen. Therefore the catalytic photoxidation of $n-$ type semiconductors will be one of the prospective methods for aquatic environmental detoxification having a several advantages over the conventional methods such as adsorption by GAC, Air Stripping 
and chemical oxidation methods. Several reports have appeared on the photocatalytic processes to dispose of environmentally harmful or carcinogenic organics at a semiconductor-water interface. For instance, halogenated aromatics ${ }^{1,}$ aliphatic compounds ${ }^{2-5}$, organophosphorus ${ }^{6,7}$, surfactants ${ }^{8,9}$ and others chemicals ${ }^{10}$ have been mineralized in to nontoxic final products of $\mathrm{CO}_{2}$ and corresponding mineral acids. With regards to the pesticides, chlorinated ${ }^{11,12}$ and organophosphorus ${ }^{13,14}$ are mainly highlighted due to their high toxicity to the environment.

Though the heterogeneous photocatalysis is superior technology than the other but it suffers from some disadvantages ${ }^{15}$ such as separation of photocalyst after treatment, UV light absorption, low overall efficiency and proper reactor design. In order to separation of photocatalyst after treatment, many attempt has been made that is immobilization of photocatalyst on various support such as activated carbon $^{16}$, glass ${ }^{17}$, ceramics ${ }^{18}$, Zeolite ${ }^{19}$ etc. To extend the light absorption to the visible zone the semiconductor oxide doped with the metal ion or various dyes or metal complexes modify its surface $^{20,21}$. Immobilization of photocatalyst on the support have a some problem like mass transfer and physical stability while in case of doping, the doped metal ion are accumulate on the surface of the photocatalyst and organic dyes or metal complexes undergoes degradation during the course of reaction.

The photocatalytic degradation of pesticide means insecticides and herbicides by heterogeneous photocatalysis was studied largely. Organochlorine or organophosphate pesticides are well studied. The fungicides that are use for the safety of food grain before the production and after production are not well studied

This work examined the photodegradation of thiram in neat $\mathrm{TiO}_{2}$ slurries as well as prepared $\mathrm{TiO}_{2} \sim \mathrm{PVA}$ polymer composite under UV and visible light illumination in presence of oxygen. According to the literature it is first report of degradation of thiram by heterogeneous photocatalyst in aqueous medium. The effects of initial concentration on the rate of degradation were examined. kinetics of $\mathrm{CO}_{2}$ evaluation as well as $\mathrm{NO}_{3}{ }^{-}$and $\mathrm{SO}_{4}{ }^{2-}$ formation was monitor during the course of reaction. On the basis analysis we proposed a possible path for the degradation by heterogeneous photocatalyst.

\section{Experimental}

All the chemicals and reagent were used throughout the experiment of A.R. grade. Doubly distilled water was used for the preparation of all solutions required for the experiment. Polyvinyl alcohol (Mw $=1,25000)$ was purchased from $\mathrm{Sd}$ fine chemical. $\mathrm{TiO}_{2}$ was supplied by Qualigen fine chemical $(100 \%$ anatase). Sodium hydroxide (Merck) and sulphuric acid (Merck) were used to adjust the $\mathrm{pH}$ of solution. Thiram of technical grade was purchased from Yawalkar pesticides Ltd. Nagpur.

Procedure for the preparation of polymer composite is overview as, the mixture of the slurry of $\mathrm{TiO}_{2}$, aqueous solution of polyvinyl alcohol and $25 \mathrm{ml} 0.1 \mathrm{~N} \mathrm{H}_{2} \mathrm{SO}_{4}$ are reflux for 6 hours. After refluxing add a desired amount of ammonia solution to get the resultant $\mathrm{TiO}_{2} \sim \mathrm{PVA}$ polymer composite. The prepared polymer composite of $\mathrm{TiO}_{2}$ and polyvinyl alcohol is able to absorb the light in visible region this was confirmed by diffuse reflectance study.

Photolysis of aqueous solution of Thiram and $100 \mathrm{mg}$ of $\mathrm{TiO}_{2}$ immobilized in PVA polymer network $\left(\mathrm{PVA} \sim \mathrm{TiO}_{2}\right)$ and/or neat $\mathrm{TiO}_{2}$ was carried out in a circular glass reactor (designed and fabricated in our laboratory). Similar study was carried out with neat $\mathrm{TiO}_{2}$. A high-pressure mercury lamp (125 W Phillips, HPL) was used as a UV light source while Halogen lamp (50W/12V/36D, Phillips Essential) was used as a visible light source. During the photolysis experiment air was bubbled in a solution continuously as a source of oxygen. Aliquots of the reaction mixture were withdrawn and without any other treatment thiram concentration is determined spectrophotometrically ${ }^{22}$ using UVVisible spectrophotometer (GBC-10e). In case of use of neat $\mathrm{TiO}_{2}$, Aliquots of the reaction mixture were withdrawn and suspensions were filtered through $0.2 \mu \mathrm{m}$ Millipore discs prior to a quantitative determination of thiram spectrophotometrically. Formation of $\mathrm{CO}_{2}$ was monitored by conductivity measurement of barium hydroxide solution $^{23}$ by conductivity meter. Analysis of Nitrate and sulphate carried out according standard procedure ${ }^{24}$. 


\section{Results and Discussion}

The effect of neat $\mathrm{TiO}_{2}$ and prepared $\mathrm{TiO}_{2} \sim \mathrm{PVA}$ polymer composite on the degradation of thiram under UV illumination in aqueous medium has shown in fig 1 while The effect of neat $\mathrm{TiO}_{2}$ and prepared $\mathrm{TiO}_{2} \sim \mathrm{PVA}$ polymer composite on the degradation of thiram under Visible illumination in aqueous medium has shown in fig 2 . For the effective degradation of thiram in aqueous medium the photocatalyst and light both are essential. In the dark or photocatalyst without light, no change is observed. In presence of UV light without photocatalyst $6 \%$ degradation of thiram was observed while in presence neat $\mathrm{TiO}_{2}$ and UV light $40 \%$ degradation of thiram was observed within a one hour of reaction time. Similarly in presence of prepared $\mathrm{TiO}_{2} \sim \mathrm{PVA}$ polymer composite and UV light $47 \%$ degradation was observed within a one hour of reaction time. In case of only Visible light irradiation only $0.3 \%$ degradation of thiram was observed while similar results are obtained when neat $\mathrm{TiO}_{2}$ was used as a photocatalyst under visible light irradiation only $0.5 \%$ degradation of thiram was observed. When Prepared $\mathrm{TiO}_{2} \sim \mathrm{PVA}$ polymer composite was used as a photocatalyst under visible light irradiation $43 \%$ degradation of thiram was observed. From the above it is clear that under UV illumination the thiram undergoes degradation but degradation is very slow while in combination with photocatalyst the degradation of thiram is very fast. It is very surprising when neat $\mathrm{TiO}_{2}$ used for the degradation of thiram under UV light $40 \%$ degradation within a one hour of reaction time observed while in case of prepared $\mathrm{TiO}_{2} \sim \mathrm{PVA}$ polymer composite the $47 \%$ degradation of thiram was observed within same time. This is may be due to the competitive adsorption of the thiram or reactive intermediate on the surface of the $\mathrm{TiO}_{2}$ which decrease the ${ }^{-} \mathrm{OH}$ active site which indirectly decrease the formation of ${ }^{\circ} \mathrm{OH}$ radical which is a power of the photocatalysis reaction ${ }^{25}$. Adsorption study confirmed that there is no adsorption of thiram on prepared $\mathrm{TiO}_{2} \sim \mathrm{PVA}$ polymer composite while thiram adsorption was observed in case of neat $\mathrm{TiO}_{2}$. We assume that similarly may be the reactive intermediate formed during the course of reaction was adsorbed on the surface of neat $\mathrm{TiO}_{2}$ not in the case of prepared $\mathrm{TiO}_{2} \sim \mathrm{PVA}$ polymer composite. In presence of Visible light or visible light with neat $\mathrm{TiO}_{2}$ no significant degradation of thiram was observed while prepared $\mathrm{TiO}_{2} \sim \mathrm{PVA}$ polymer composite act as photocatalyst under visible light and $43 \%$ degradation of thiram was observed within a one hour. Earlier study reflects that light required for the excitation of neat $\mathrm{TiO}_{2}$ having a wavelength lesser that $365 \mathrm{~nm}$. It is confirmed that the visible light source not emitted a radiation having wavelength lesser than $400 \mathrm{~nm}$. Hence under visible light $\mathrm{TiO}_{2}$ is not act as a catalyst. In case of prepared $\mathrm{TiO}_{2} \sim \mathrm{PVA}$ polymer composite may be the surface of the $\mathrm{TiO}_{2}$ was modified by the polyvinyl alcohol like that of organic dyes or metal complexes which was confirmed by diffuse reflectance study. As a result prepared polymer composite is act as a photocatalyst under the visible light.

The effect of initial concentration of thiram on the photocatalytic degradation rate was investigated over the concentration range of $(1.0-5.0) \times 10^{-3} \mathrm{~mol} \mathrm{lit}^{-1}$, the pollutant concentration is a very important parameters in water treatment. Experimental results for the neat $\mathrm{TiO}_{2}$ are represented in the Figure 3 and Table I while for the prepared $\mathrm{TiO}_{2} \sim \mathrm{PVA}$ polymer composite are represented in the Figure 4 and Table II, together with the "r" value for each of the fitted line. In case of neat $\mathrm{TiO}_{2}$, the results show that the degradation rate depends on the initial concentration of thiram. The rate constant $\mathrm{k}$ decreases with increase in the initial concentration of thiram. This finding indicates that the degradation kinetics of thiram is not a simple first order but pseudo first order. In case of prepared $\mathrm{TiO}_{2} \sim \mathrm{PVA}$ polymer composite, the results shows that the degradation rate was not depends on the initial concentration of thiram and rate constant $\mathrm{k}$ not decreases with increase the initial concentration of thiram as such like neat $\mathrm{TiO}_{2}$. This finding indicates that in the case of prepared $\mathrm{TiO}_{2} \sim \mathrm{PVA}$ polymer composite the degradation kinetics of thiram is simple first order.

Furthermore, the slopes of the lines in Figure 3 and the $\mathrm{k}$ values in Table $\mathbf{I}$ show that the degradation rate decreases rapidly at low initial thiram concentration when neat $\mathrm{TiO}_{2}$ used as a photocatalyst. As the initial concentration increases, it begins to decrease slowly. As it can be seen from the values given in the Table $\mathbf{I}$, the change in the rate constant is $13.21 \times 10^{-4} \mathrm{~min}^{-1}$ when the initial thiram concentration increases from $1.0 \times 10^{-4}$ to $2.0 \times 10^{-4} \mathrm{~mol} \mathrm{l}^{-1}$. However when the initial concentration increases from $4.0 \times 10^{-4}$ to $5.0 \times 10^{-4} \mathrm{~mol}^{-1}$, the decrease in the rate constant is much less, that is $0.44 \times 10^{-4} \mathrm{~min}^{-1}$. The different results are obtained when prepared $\mathrm{TiO}_{2} \sim \mathrm{PVA}$ polymer composite was used as a photocatalyst. The slopes of the lines of the Figure 4 and the k values in the 
Table II show that the degradation rate was not decreases when the initial concentration increases. Even though the concentration was increases from $1.0 \times 10^{-4}$ to $2.0 \times 10^{-4} \mathrm{~mol}^{-1}$ the change in the rate constant was not observed. When the concentration was increases from $4.0 \times 10^{-4}$ to $5.0 \times 10^{-4} \mathrm{~mol}^{-1}$, the decreases of the rate constant is observed that is $1.12 \times 10^{-4}$. This indicate that other than adsorption other parameter also affect the rate of the degradation of the pollutants.

Table I: Effect of initial concentration of thiram on photodegradation rate when neat $\mathrm{TiO}_{2}$ used as a photocatalyst.

\begin{tabular}{ccc}
\hline $\mathrm{Co}\left(10^{-4} \mathrm{~mol} \mathrm{l}^{-1}\right)$ & $\mathrm{k}\left(10^{-4} \mathrm{~min}^{-1}\right)$ & $\mathrm{r}$ \\
\hline 1.0 & 17.40 & 0.9485 \\
2.0 & 4.19 & 0.9972 \\
3.0 & 1.80 & 0.9995 \\
4.0 & 1.10 & 0.9998 \\
5.0 & 0.66 & 0.9999 \\
\hline
\end{tabular}

Table II: Effect of initial concentration of thiram on photodegradation rate when Prepared $\mathrm{TiO}_{2} \sim \mathrm{PVA}$ polymer composite used as a photocatalyst.

\begin{tabular}{ccc}
\hline $\operatorname{Co}\left(\times 10^{-4} \mathrm{~mol} \mathrm{l}^{-1}\right)$ & $\mathrm{k}\left(10^{-4} \mathrm{~min}^{-1}\right)$ & 0.9174 \\
1.0 & 24.33 & 0.9174 \\
2.0 & 24.33 & 0.9313 \\
3.0 & 22.33 & 0.9444 \\
4.0 & 20.21 & 0.9507 \\
5.0 & 19.09 & \\
\hline
\end{tabular}

Initial concentration dependence of the photodegradation rate of thiram when neat $\mathrm{TiO}_{2}$ was used as a photocatalyst and can be based on the fact that the degradation reaction occure on $\mathrm{TiO}_{2}$ particles as well as in the solution ${ }^{25}$. On the surface of $\mathrm{TiO}_{2}$ particles, the reaction occurs between ${ }^{\circ} \mathrm{OH}$ radicals, generated at the active $\mathrm{OH}^{-}$sites and thiram molecule from the solution. When the initial concentration is high, the number of these available active sites is decreased by thiram molecules because of their competitive adsorption on the $\mathrm{TiO}_{2}$ particles. In this case, the rate of transfer of thiram molecule from the solution does not affect degradation rate. However, when the initial concentration is low the transfer rate plays an important role during the course of reaction. When prepared $\mathrm{TiO}_{2} \sim \mathrm{PVA}$ polymer composite was used as a photocatalyst adsorption does not affect the degradation rate which was clear from the data. May be in this case the opacity and light scattering is a reason for decrease of the degradation rate at high concentration ${ }^{26}$.

In view of health hazards the end product of the degradation of pollutants is most important. Hence we monitor the $\mathrm{CO}_{2}, \mathrm{SO}_{4}{ }^{2-}$ and $\mathrm{NO}_{3}{ }^{-}$analysis during the course of reaction. Formations of these end products are represented in the Figure 5. Form the Figure 5; it is clear that the $\mathrm{CO}_{2}, \mathrm{SO}_{4}{ }^{2-}$ and $\mathrm{NO}_{3}{ }^{-}$are the end product of the photocatalysed degradation of thiram. No nitrite formation observed during the course of reaction. It is interesting to note that up to $100 \mathrm{~min}$ of time no sulphate or nitrate was detected during the course of reaction. $\mathrm{CO}_{2}$ analysis show that within a 100 minute of reaction time $59.2 \%$ carbon dioxide is recovered $(3.55 \mathrm{mmol} \mathrm{C})$ while remaining carbon dioxide is recovered in next 50 minutes $(2.35 \mathrm{mmol} \mathrm{C})$. Further reaction does not give more $\mathrm{CO}_{2}$, means that remaining $0.1 \mathrm{mmol}$ carbon was not recovered as a $\mathrm{CO}_{2}$. This suggested that some volatile carbon containing compound may be formed during the course of the reaction or it is may be the experimental error. 


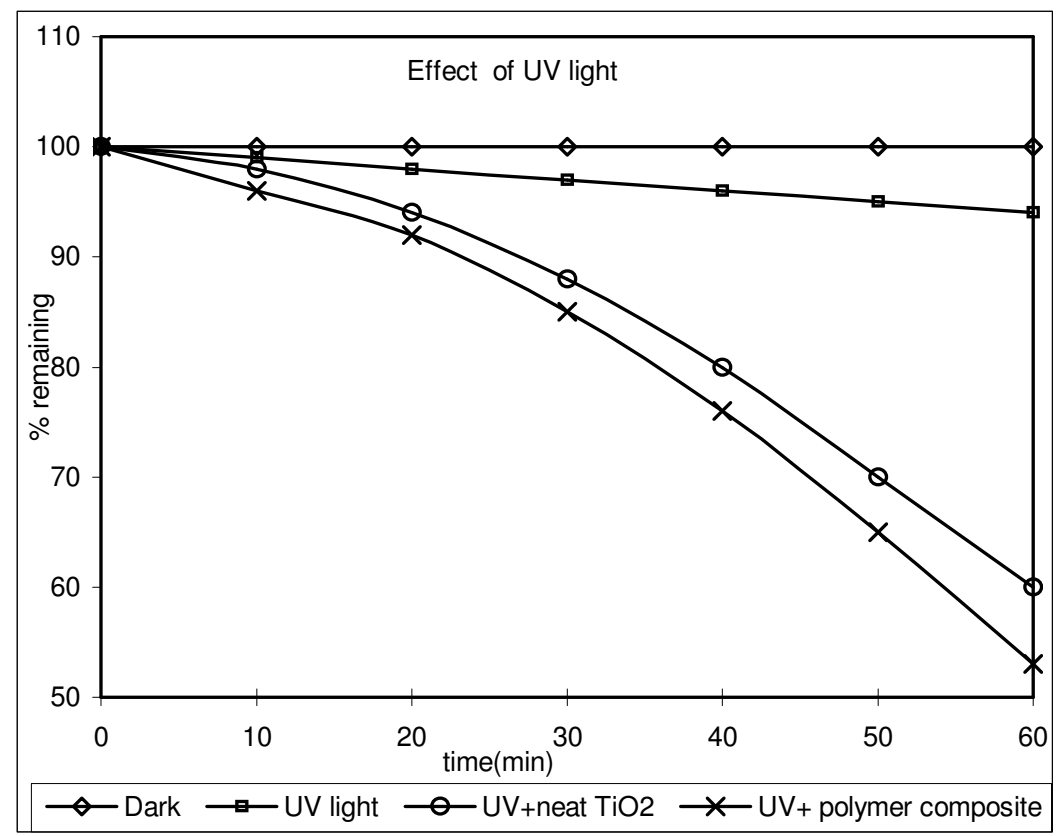

Figure 1: Photocatalytic disappearance of thiram-effect of UV light $(\diamond)$ dark, $(\square)$ With UV light, (०) with UV light $\&$ neat $\mathrm{TiO}_{2}$ and $(\times)$ with UV light and prepared $\mathrm{TiO}_{2} \sim \mathrm{PVA}$ polymer composite

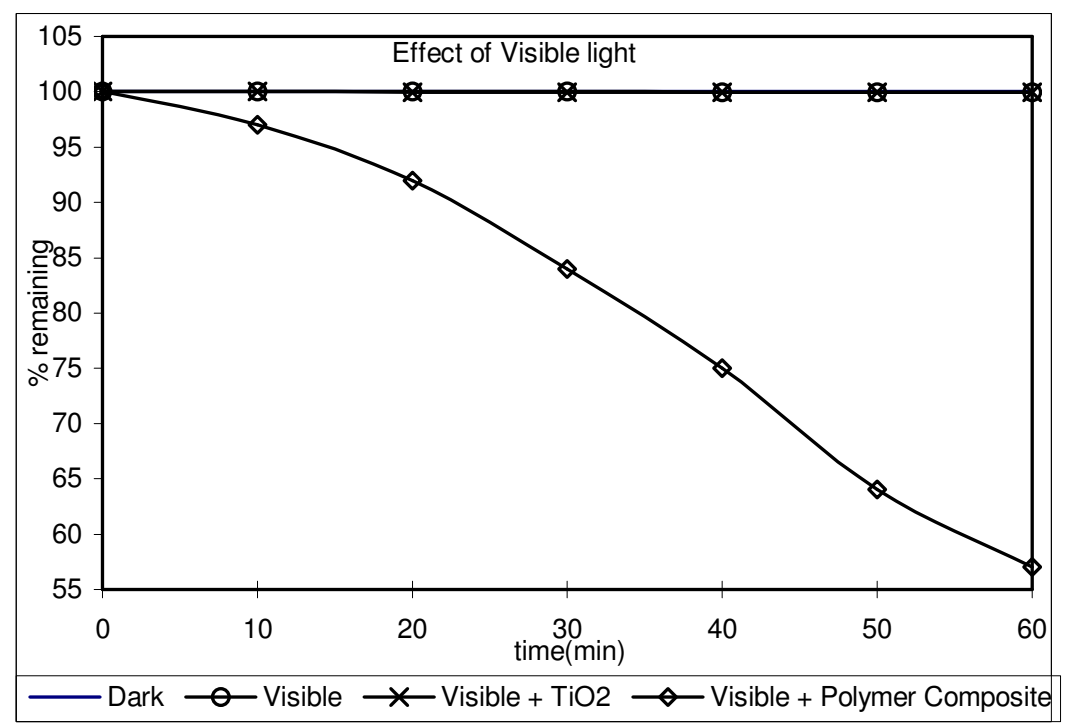

Figure 2: Photocatalytic disappearance of thiram-effect of visible light (-----) dark,

$(\circ)$ With visible light light, $(\times)$ with visible light and prepared

$\mathrm{TiO}_{2} \sim \mathrm{PVA}$ polymer composite and $(\diamond)$ with Visible light \& neat $\mathrm{TiO}_{2}$ 


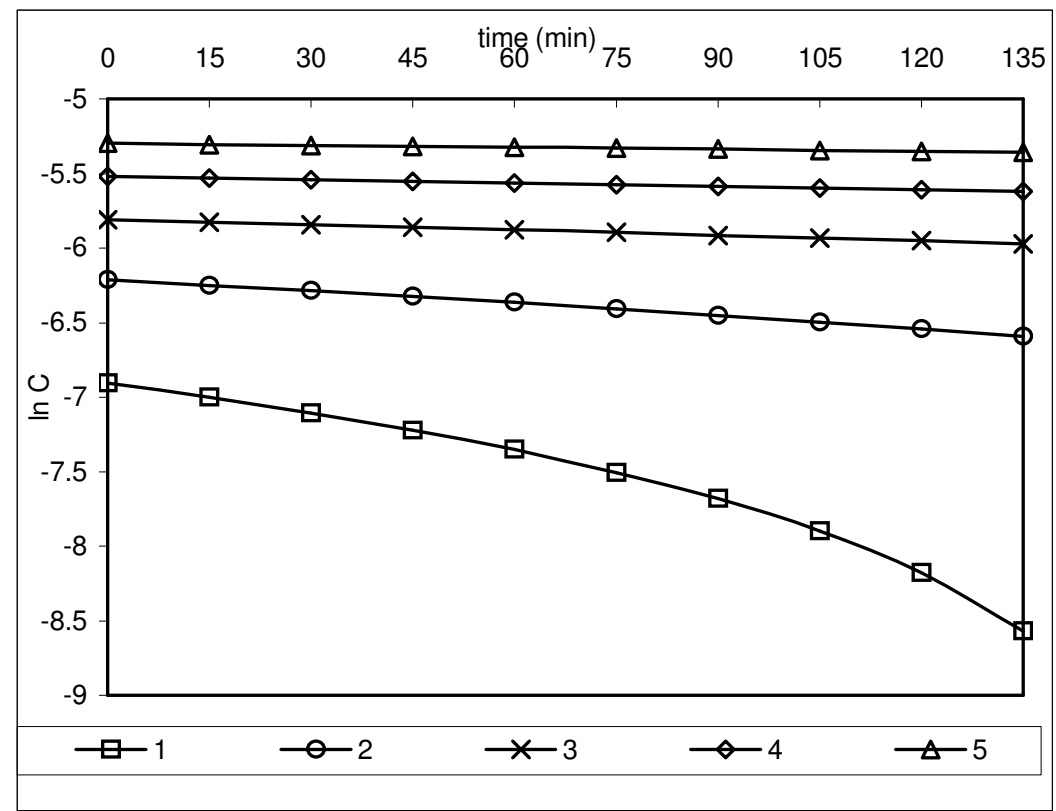

Figure 3: Effect of initial concentration on the photodegradation rate of thiram when neat $\mathrm{TiO}_{2}$ used as a photocatalyst $(\square) 1.0 \times 10^{-4} \mathrm{~mol} \mathrm{l}^{-1}$,

(○) $2.0 \times 10^{-4} \mathrm{~mol} \mathrm{l}^{-1}$, (×) $3.0 \times 10^{-4} \mathrm{~mol} \mathrm{l}^{-1},(\diamond) 4.0 \times 10^{-4} \mathrm{~mol} \mathrm{l}^{-1}$ (A) $5.0 \times 10^{-4} \mathrm{~mol} \mathrm{l}^{-1}$

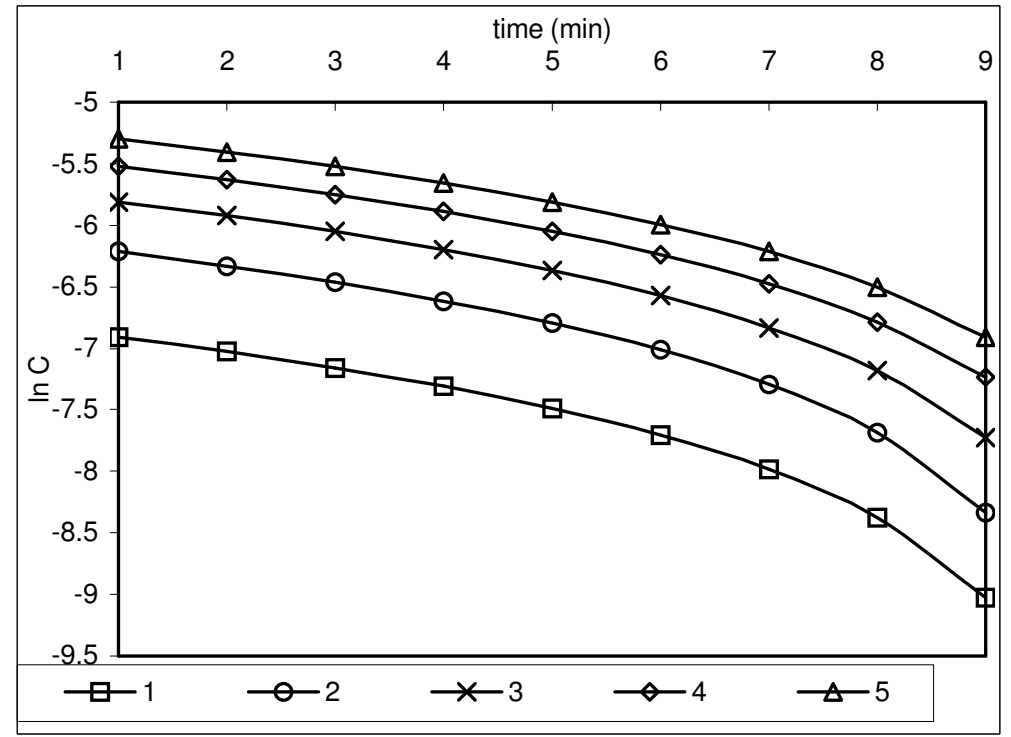

Figure 4: Effect of initial concentration on the photodegradation rate of thiram when prepared $\mathrm{TiO}_{2} \sim \mathrm{PVA}$ polymer composite used as a photocatalyst
(ㅁ) $1.0 \times 10^{-4} \mathrm{~mol} \mathrm{l}^{-1}$, (०) $2.0 \times 10^{-4} \mathrm{~mol} \mathrm{l}^{-1}$, (×) $3.0 \times 10^{-4} \mathrm{~mol} \mathrm{l}^{-1}$,
$(\diamond) 4.0 \times 10^{-4} \mathrm{moll}^{-1}(\Delta) 5.0 \times 10^{-4} \mathrm{~mol} \mathrm{l}^{-1}$ 


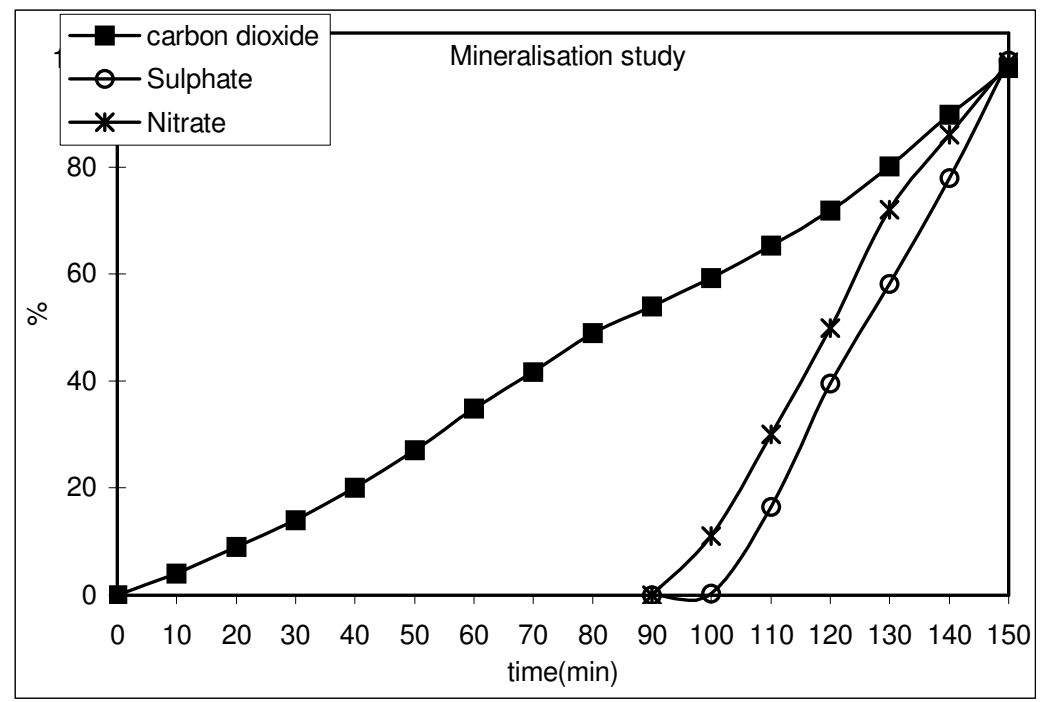

Figure 5: Formation of nitrate, sulphate and evolution of $\mathrm{CO}_{2}$ during the Photocatalytic degradation of thiram under visible light irradiation. (घ) $\mathrm{CO}_{2}(\mathrm{O})$ sulphate $(\Delta)$ nitrate

Based on the forgoing analysis, a reaction mechanism for the photocatalytic degradation of thiram by prepared $\mathrm{TiO}_{2} \sim \mathrm{PVA}$ polymer composite under visible light irradiation is proposed as follows. ${ }^{\circ} \mathrm{OH}$ radical generated due to the interaction of hole with water molecule after the excitation of photocatalyst. ${ }^{\circ} \mathrm{OH}$ radical attack on the thiram molecule and $\mathrm{N}$-demethylation occure. $\mathrm{N}$ demethylation was supported by the $\mathrm{CO}_{2}$ analysis. In first 100 minutes course of reaction the 59.2\% $\mathrm{CO}_{2}$ was recovered which was equal to the theoretical value for the four methyl group that is $60 \%$, also no Nitrate or sulphate detected up to the same time. The sulphate and nitrate formation and remaining $40 \%$ carbon recovered simultaneously. Form this we assume that the demethylation is an initial process occure during the degradation of thiram. Further attack on the demethylated thiram leads to the formation of $\mathrm{CO}_{2}$, nitrate, and sulphate.

\section{Conclusion}

It is concluded that the thiram, a fungicides used for the agricultural purposes undergoes degradation in presence of prepared $\mathrm{TiO}_{2} \sim \mathrm{PVA}$ polymer composite and visible light irradiation. Compare to the neat $\mathrm{TiO}_{2}$ the prepared $\mathrm{TiO}_{2} \sim \mathrm{PVA}$ polymer composite is a best photocatalyst in term of rate of reaction, photocatalyst under visible light irradiation, no adsorption of pollutant or reactive intermediate or end products.

\section{Acknowledgement}

The authors wish to thanks the Head of the Department of Chemistry, Nagpur University, Nagpur for the use of the Facilities. One of the authors(S.R.T.) thanks Principal, Science College, Nagpur to permit for the research work.

\section{References}

1 Borello R, Serpone N and Hidaka H, Environ.Toxicol.Chem 1989, 8, 997.

2 Pruden A L and Ollis D F Environ. Sci. Technol. 1983, 17, 628.

3 Pruden A L and Ollis D F J.Catal. 1983, 82, 418. 
$4 \quad$ Nguyen T and Ollis D F J. Phys.Chem. 1984, 88, 3386.

$5 \quad$ Mattews R W Water Res. 1986, 20, 569.

$6 \quad$ Gratzel C K and Gratzel M J. Mol. Catal. 1987, 39, 347.

$7 \quad$ Harada K.; Tanaka K. New J.Chem. 1987, 11, 597.

8 Hidaka H, Serpone N and Gratzel M J. Photochem. Photobiol A:Chem 1989, 47, 103.

9 Hidaka H, Serpone N and Pelizzetti E J. Mol. Catal 1990, 59, 279.

10 Pelizzetti E and Minero C Adv.Colloids Interface Sci. 1990, 32, 271.

11 Pelizzetti E and Serpone N Chemosphere 1987, 16, 1165.

12 Pelizzetti E and Minero C, Chemosphere 1989, 18, 1437.

13 atthews R W, J. Catal. 1988, 111, 264.

14 Pehkonen S and Zhang Q, Critical Rev. Env. Sci. Technol 2002, 32, 17.

15 Litter M Appl. Catal. B: Enviton. 1999, 23, 89.

16 Matos J, laine J and Hermann J. Appl.Catal B: Environ. 1998, 18, 281.

17 Matthews R W J.Phys.Chem 1987, 91, 3328.

18 Sawunyama P and Okada K. Mater. Res. Bull. 1998 , 33, 795.

19 Tanaka K Appl. Catal. A: General 2002, 234, 155.

20 Rabani J J. Photochem. Photobiol A:Chem 2002, 148,17.

21 Anpo M J Photochem. Photobiol A:Chem 2002, 148, 257.

22 AOAC official method 972.29.

23 Matthews R W Anal. Chim. Acta 1990, 233, 171.

24 Taras H J, Greenberg A E, Hoak R D and Rand M C, Standard methods for the Examination of Water \& Wastewater, American Health Association : Washington, DC, 1990, pp. 461.

25 Al-Ekabi H, and De Mayo P J. Phys.Chem. 1986, 90, 4075.

26 San N, Hatipoglu A and Cinar Z. J. Photochem. Photobiol A:Chem 2002, 146,189. 


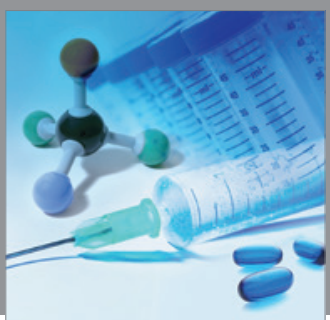

International Journal of

Medicinal Chemistry

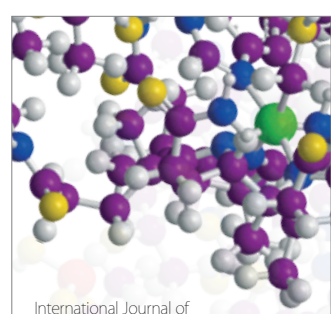

Carbohydrate Chemistry

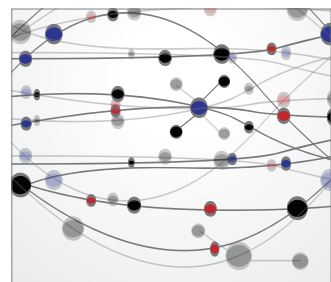

The Scientific World Journal
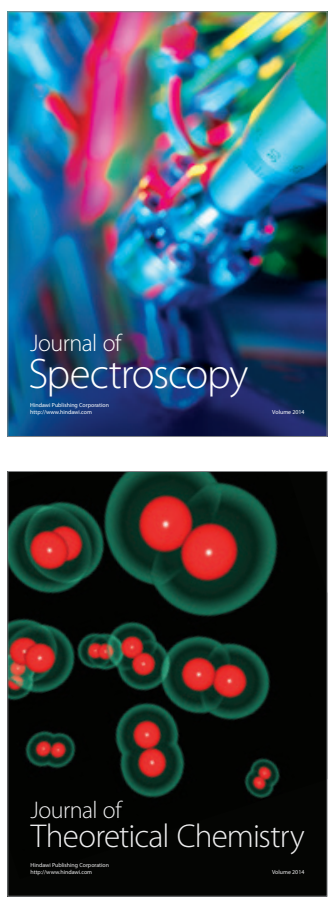
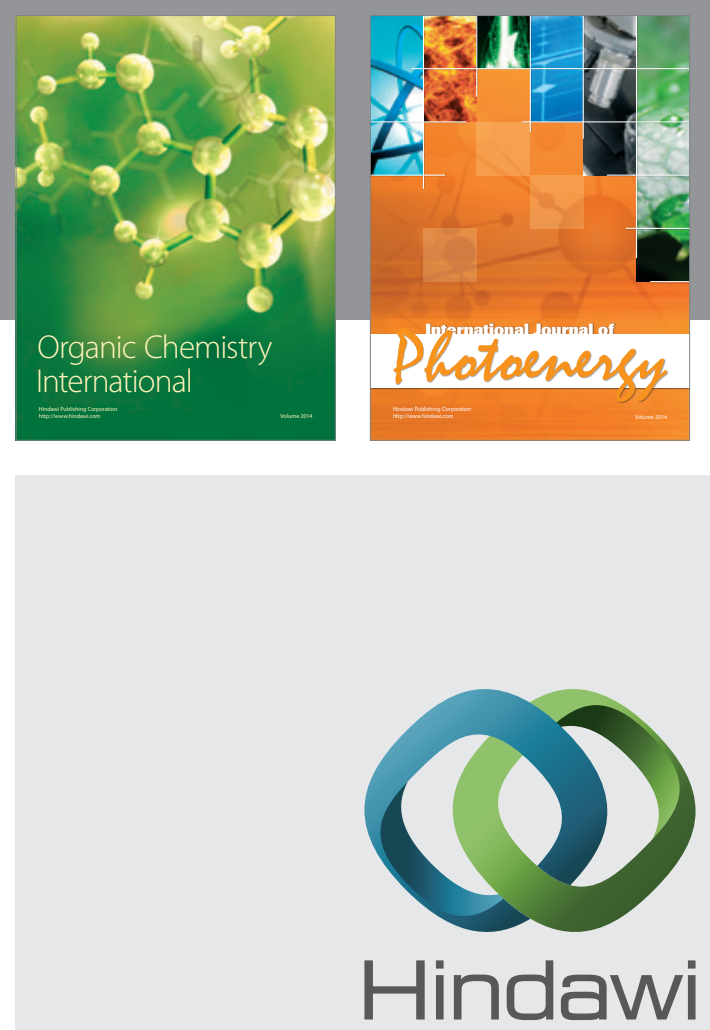

Submit your manuscripts at

http://www.hindawi.com
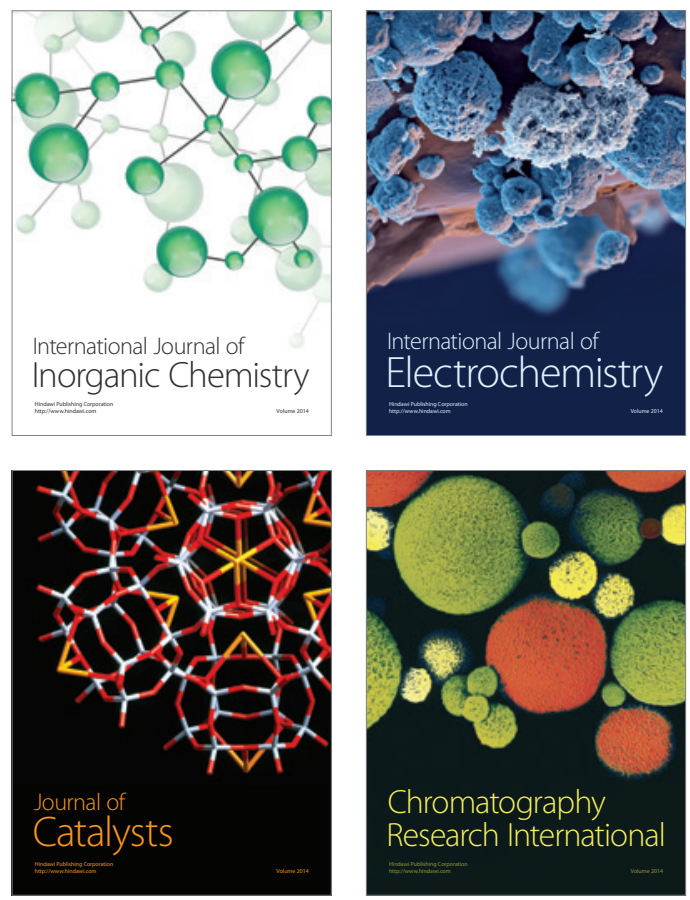
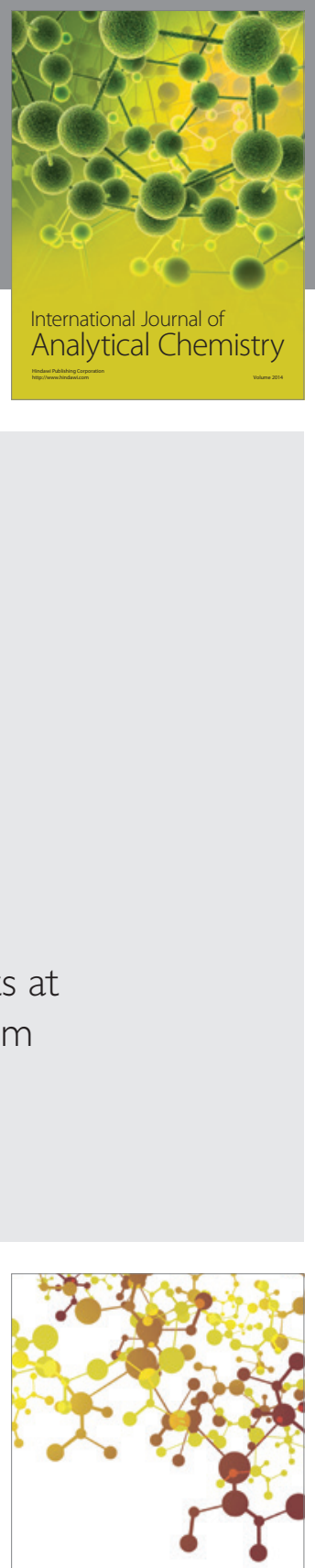

Journal of

Applied Chemistry
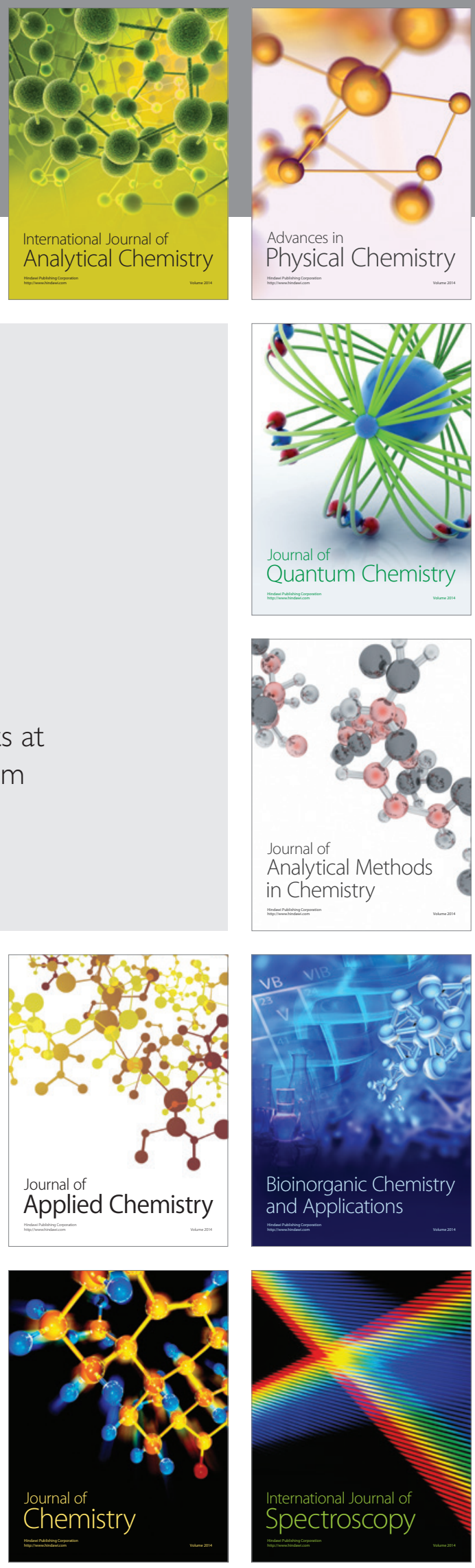